\title{
The Effect of a Trans-Theoretical Model Based Intervention on Physical Exercises Behaviour among Postpartum Women at Benha City, Egypt
}

\author{
Hanan Abd Elwahab El Sayed ${ }^{1}$, Heba Abdel-Fatah Ibrahim ${ }^{2, *}$, \\ Samia Abd Elhakeem H Aboud ${ }^{2}$, Ahlam Elahmady Mohamed Sarhan ${ }^{1}$ \\ ${ }^{1}$ Community Health Nursing, Benha University, Benha, Egypt \\ ${ }^{2}$ Obstetrics and Woman Health Nursing, Faculty of Nursing, Benha University, Egypt \\ *Corresponding author: heba_esmael18@yahoo.com
}

Received February 01, 2019; Revised March 04, 2019; Accepted April 12, 2019

\begin{abstract}
Background: Physical activity behaviour during the postpartum period is very important to improve maternal health and prevent complications both in the short and long term. This study aims to evaluate the effect of a trans-theoretical model based intervention on physical exercises behaviour among postpartum women at Benha City, Egypt. Methods: A quasi-experimental design was utilized. The study was conducted at family planning outpatient clinic affiliated to Benha teaching hospital. A purposive sample of 86 postpartum women were included in the present study. Three tools were used for data collection; first tool: structured interviewing schedule to collect data about the subjects' demographic characteristics, medical and obstetric history and knowledge towards postpartum exercises. Second tool; the trans-theoretical model of behaviour change questionnaire, it composed of the four main dimensions that are stage of change, self-efficacy, decisional balance (pros and cons), experiential and behavioural process of change. Third tool; international physical activity questionnaire short-form to assess the postpartum physical activity level. Results: The mean age of the studied women was $28.88 \pm 5.89$ years. There were statistically significant improvements $(\mathrm{P}<0.05)$ regarding to women' knowledge, and all constructs of trans-theoretical model which include self-efficacy, decisional balance, experiential and behavioural processes of change after the transtheoretical model based intervention as compared to before. Conclusion: The trans-theoretical based intervention was efficient in improving women's knowledge, postpartum exercise behaviour. This was observed in increasing women's self-efficacy, decisional balance pros, experimental and behavioural processes of change. While reducing decisional balance cons. Recommendation: The nurse should implement trans-theoretical model based interventions for postpartum women to promote postpartum exercise behaviour.
\end{abstract}

Keywords: trans-theoretical model, physical exercises behaviour, postpartum women

Cite This Article: Hanan Abd Elwahab El Sayed, Heba Abdel-Fatah Ibrahim, Samia Abd Elhakeem H Aboud, and Ahlam Elahmady Mohamed Sarhan, "The Effect of a Trans-Theoretical Model Based Intervention on Physical Exercises Behaviour among Postpartum Women at Benha City, Egypt.” American Journal of Nursing Research, vol. 7, no. 3 (2019): 342-353. doi: 10.12691/ajnr-7-3-15.

\section{Introduction}

The postpartum period is the six weeks after child birth, in which the body undergoes major physiological changes. It is an important evolution time for women affecting specially her physical and mental health. Life threatening complications can occur during postnatal period so it is the important part of maternal health care. The postpartum period and care during this period should be prolonged to one year rather than just six to eight weeks, since some physiological adaptations of postpartum period occur to at least at this time, and breastfeeding is now encouraged for at least one year after childbirth. [1]

Postpartum exercises are exercises performed after childbirth and started as soon as possible. Providing women with safely levels of physical activity earlier after childbirth may give additional support to them. It gives benefits to both physical and psychological health during the postpartum period. [2]

Many health benefits are accompanying with practicing small level of physical activity behaviours during postpartum period. These benefits include an earlier return to weight shape before pregnancy, increase the level of fitness and increased ability to cope with the newborn baby demands. [3] Moreover, maintain ante version position of the uterus, and improve drainage of lochia. Early ambulation and breathing exercises are recommended during this period to reduce the risk of deep venous thrombosis and maintain respiratory function. In addition Kegel exercises strengthen the pelvic floor muscles, and decrease the risk of genital organ prolapse and stress urinary incontinence. [4] 
Moreover, participation in postpartum exercise enhance psychological well-being, increase self-esteem and confidence of postnatal women by getting back in shape. In addition regular physical exercise has a positive impact on psychological health including reduced symptoms of postpartum depression and baby blues by preventing any tension and anxiety that woman may feel. [5] According to Davies et al. postpartum women should practice physical activity to decrease postpartum complications such as puerperal infection and/or postpartum hemorrhage. [6].

Physical exercise behaviours during the postnatal period is very essential to improve maternal health and prevent short and long term postpartum complications. [7] Therefore, it is important for postpartum women to be aware of medical contraindications and practice at least half an hour of exercise on most days of the week, with increase the frequency and duration of exercise throughout the week as those who were physically active before pregnancy can remain to be so. [8]

The starting and maintenance of regular exercise is generally a challenging and difficult behaviour. Puerperas face many challenges to exercise during the postpartum period, so they should understand the pros, cons, and beliefs toward postpartum physical activity that can help to more efficiently develop physical exercise programs. $[9,10]$ Most of postpartum women did not practice exercise due to exhaustion, episiotomy pains, discomfort, and a lack of educational intervention implementation at health care centers. So a sustainable educational programme should be developed by the registered nurses on postpartum physical exercise in postnatal units. [11]

Comprehensive exercise programs that focuses on muscular strength, endurance, and flexibility plays a vital role in women's health and wellbeing. [12] Many researches indicate the successful use of Trans-theoretical Model (TTM ) based interventions to develop most of health behaviors among different populations. For example physical activity program enrollment [13].

The trans-theoretical model provides a framework for providing concepts and measurement of behaviour change, also enabling promotion strategies that are individualized and easily adapted. The TTM was developed as a comprehensive model of behaviour change, including behavioural, cognitive and temporal characteristics into a integrated approach for behaviour change. The constructs defined in the TTM consist of the processes of change, the stages of change, self-efficacy and decisional balance. Stage of change categorizes individuals regarding their progression towards physical activity and is postulated to share with the other TTM constructs. So, processes of change, self-efficacy and decisional balance, are expected to change as they move through the stages of change. [14] An advantage of TTM is that health care consultants are able to treat individuals along different phases of readiness to change their health behaviours. [15]

Although the success of TTM, use of the TTM has concentrated more on behaviour change, and there are a number of social, intellectual and behavioural variables found to significantly differ across the stages of change. [16] There is a need for behavioural interventions to stimulate the physical exercise among puerperas. [17] For this reason, recognizing effective factors in constructing behaviour will make it is easy to modify this behaviour. Few studies were done in this respect which did not reflect all aspects of education and a small number of mothers contribute in this period. [18] Consequently, special interventions are required to help women integrate moderate physical activity and to prevent sedentary behaviour that occur during postpartum period. [19]

\subsection{Significance of the Study}

There are important physical and psychological health and wellbeing benefits from practicing regular physical exercise during postnatal period. Physical activity contributes to the prevention and treatment of many of disabling physical and psychological conditions, including: malignant tumors, cardiac disease, diabetes mellitus, depression ,osteoporosis and obesity. [20] It is estimated that $75 \%$ of Egyptian females, over the age of 30 , are overweight or obese. [21] Physical inactivity is a main cause of obesity as it causes an energy imbalance between calories intake and expenditure. [22] Obesity is also associated with parity among Egyptian females. Pregnancy may contribute to obesity through decreasing the ability of participation in strenuous activity. [23] World Health Organization, recommends that all postpartum women should be encouraged to activate as soon as possible after birth. They should be encouraged to do moderate exercise and make special time to rest during the postnatal period. [24] Since there is no sufficient evidence on the effect of a TTM based intervention on postpartum exercises behaviour among Egyptian women, it is important to conduct such study.

\subsection{Aim of the Study}

To evaluate the effect of intervention based a transtheoretical model on physical exercises behaviour among postpartum women at Benha city. This aim attained through:

- Assessing knowledge and exercise behavior of postpartum women using trans-theoretical model construct to identify their needs.

- Designing and implementing an educational intervention based on trans-theoretical model according to postpartum women' needs.

- Evaluating the effect of an educational intervention on postpartum women' knowledge and physical exercises behaviour using trans-theoretical model construct.

\subsection{Research Hypothesis}

Knowledge and postpartum physical exercises behaviour of the study participants will be improved after implementation of an educational intervention based on trans-theoretical model of behaviour change.

\section{Subjects and Methods}

\subsection{Research Design}

A quasi-experimental research design (pre/post-test) was used to test the study hypothesis. 


\subsection{Setting}

The study was conducted at family planning outpatient clinic of Benha teaching hospital, Benha city.

\subsection{Sample Type and Criteria}

A purposive sample of 86 postpartum women were taken for the study and achieved the following inclusion criteria; women undergone normal vaginal delivery with or without episiotomy, 3-12 months post-delivery, in the pre-contemplation, contemplation or preparation stage of change and interested to participate in the study. Those with physical exercise restriction as a result of any diseases, or having complication during postpartum period as (postpartum hemorrhage or infection) were excluded from the study.

\subsection{Sample Size}

The study comprised a purposive sample of 86 postpartum women were attended in family planning outpatient clinic. According to statistical center of Benha teaching hospital, 2017, the postpartum women who attended family planning clinic were 860 women at the end of year 2017. 10\% of flow rate (86 women) was selected. Consequently, the sample size was 86 puerperas.

\subsection{Tools of Data Collection}

Three tools were used to conduct the study:

\subsubsection{Tool I}

Structured interviewing schedule was developed by the researchers after reviewing of related literature in Arabic language and involved two parts:

- Women' demographic data and obstetric history such as; age, income, education, occupation, residence, telephone number, weight, height, parity and lactation.

- Knowledge of the women regarding postnatal exercises. This part was used before and after implementation of intervention and included seven open-ended questions which include; definition, proper time, benefits of postnatal exercises, preparation before exercises, contraindication, different types and warning symptoms to perform postpartum exercises. Knowledge was scored on three point scale; a correct answer was scored "two", incomplete answer was scored "one" and the unknown or incorrect answer scored "zero". The total knowledge score was calculated by adding the scores for the correct answers. The total score was from 0 to 14 point. The higher scores reveal high levels of knowledge regarding postnatal exercises.

\subsubsection{Tool II}

The TTM of behavior change questionnaire, it was established and modified based on a related literature $[25,26,27]$ then translated to Arabic language. This part was used pre and post implementation of the TTM (pre/post-test format). This tool encompassed four main constructs of TTM. i. Woman's stage of change related to postnatal exercises behavior.

The five-item stage of change was designed by Marcus, et al. [25]. to assess woman's readiness for change. The studied women choose one of five statements best indicating their current intentions for postnatal exercises behavior. The 5 items stages of change scored as a following [pre-contemplation $=1$, contemplation=2, preparation=3, action=4, maintenance $=5$ ].

\section{ii. Exercise Self-Efficacy Scale (ESES).}

Self-efficacy regarding postnatal exercises behavior was assessed using ESES Kroll, et al. [26] ESES is a self-report measure include 10 statements. The participants endorsed each statement using a 4-point Likert scale. The scores were (1) for not at all true, (2) rarely true, (3) moderately true, (4) always true. The maximum score of self-efficacy $=40$.

iii. Decisional balance scale related to postnatal exercises behavior.

Decisional balance (pros and cons) were assessed using the decisional balance questionnaire contained 16 questions designed to evaluate exercise beliefs Marcus, et al. [27], 10 statements represented the Pros (positive beliefs) about postnatal exercises and 6 statements represented the Cons (obstacles) of postnatal exercises. The studied women were asked to choose on a 5-point Likert scale, in what way important every statement was with respect to their intentions to exercise, or not. The scores of (pros) were (1) for strongly disagree, (2) disagree, (3) unsure (4) agree and (5) strongly agree. While the scores of (cons) were reversed (5) for strongly disagree, (4) disagree, (3) unsure (2) agree and (1) strongly agree. Maximum score of pros $=50$ and cons $=30$.

iv. Processes of change related to postnatal exercises behavior.

Experiential and behavioural processes were evaluated by 10 elements, 5 for experiential processes which involve "consciousness raising, environmental re-evaluation, social liberation, dramatic relief, and self- re-evaluation". And 5 elements for behavioural processes which include "self-liberation, counter conditioning, stimulus control, reinforcement management and helping relationships". Each element of processes were assessed by 2 statements. The study participants indicated frequency of use for each process within the past month on a 3-point Likert- scale. The score were 1 for never, 2 for sometimes and 3 for always. Maximum score of each element $=6$. While the total score for experiential processes $=30$ and behavioural processes $=30$.

\subsubsection{Tool III}

International Physical Activity Questionnaire shortform (IPAQ-SF)

The IPAQ-SF was used to evaluate postpartum physical activity level. [28,29] The IPAQ-SF calculates physical activity during the last 7 days distributed into four sections: severe physical activity, moderate physical activity, walking and sitting.

Activity was calculated according to MET. It is a unit to calculate metabolic expenditure. For computing the total score of the form the activity durations (minutes) and the frequencies (days) are summed. The MET-minute score is calculated as the result of the summation. 
- $\quad$ Walking MET-min/week = 3.3 X walking minutes $\mathrm{X}$ number of walking days.

- $\quad$ Moderate MET-min/week =4.0 X moderate activity minutes X number of days with moderate activities.

- Severe MET-min/week $=8.0$ X severe activity minutes $\mathrm{X}$ number of days with severe activities.

Total MET-min/week $=($ walking + moderate + severe $)$ MET-min/ week.

According to Bozkus et al. [30] the classification is made for three activity levels according to the score obtained from the summation of walking, moderate, and severe

- $\quad$ Low level $=<600 \mathrm{MET}$-min/week,

- $\quad$ Moderate level $=600-3000 \mathrm{MET}$-min/week,

- $\quad$ High level = >3000 MET-min/week

\subsubsection{Tools Validity}

The tools were revised for validity of the content by a panel of six experts, three in obstetrics, woman health nursing field and three in community health nursing field to ascertain relevance and comprehensiveness.

\subsubsection{Tools Reliability}

Cronbach's Alpha coefficient test was used to test reliability which displayed that the tools involved homogenous items as showed by the moderate to high reliability of each tool. The internal consistency of knowledge was 0.74; Self-efficacy Scale was 0.88, pros was 0.74 , cons was 0.79 , experiential processes was 0.80 , behavioral processes 0.78 . and IPAQ-SF was 0.78 .

\subsection{Ethical Considerations}

Before data collection, the participants were knowledgeable about the purpose of the study. They were given an chance to reject or to join in the study. Moreover, they were informed that, their collected information would be personal and used only for the purpose of study.

\subsection{Pilot Study}

$10 \%$ of the sample (9) postpartum women was used for pilot study and were excluded from the study sample. The main purpose to assess the tools clarity and objectivity and estimate the time required to fill the tools of data collection.

\subsection{Field Work: (Intervention Construction)}

A written approval to conduct this study was taken from the Dean of faculty nursing to director of Benha teaching hospital. Other written official letter was given to the manager of the outpatient clinic, to obtain their agreement to conduct the study after clarifying its purpose. The study was carried out through four main phases: assessment, planning, implementation, and evaluation. These phases were carried out from beginning of December 2017 to the end of July 2018, covering along a period of 8 months. The previous setting was visited by the researchers two days/week (Sunday and Thursday) from 10.00 am to $12.00 \mathrm{pm}$ according to the plan of family planning outpatient clinic.

\subsubsection{Assessment Phase}

The researchers interviewed the women after reviewing her medical record, ensure of her health status, explained the purpose of the study, and asked for participation. Upon consent to participate, each woman was interviewed to assess demographic data, knowledge regarding postnatal exercises, as well as TTM of behaviour change questionnaire to evaluate the participants' stages of change, self-efficacy, decisional balance (pros and cons) and process of change. The data attained during this phase considered the baseline for further comparisons to evaluate the effect of TTM based intervention on postpartum exercises behaviour change. Time needed to complete of interviewing questionnaires (25 minutes). An average number of interviewed women / week 5 women.

\subsubsection{Planning Phase}

The intervention was designed by the researchers based on stage of change of each participant and level of difficulty in a form of printed Arabic booklet to satisfy the participants' deficit knowledge and strategies for exercises behaviour modification. Women are classified into three groups according to previously identified stage of change as follows A) women at pre-contemplation stage, B) contemplation stage and C) preparation stage. A booklet was designed specifically for women, in simple Arabic language to suit their level of understanding. It educates mothers about stages of change so they can put themselves in correct stage and then provides information appropriate to the stages of change. Education was given based on exercises behaviour modification at the precontemplation, contemplation and preparation stages. It comprises definition of postnatal exercises, proper time, benefits of postnatal exercises, preparation before exercises, contraindication, different types of postnatal exercises and warning symptoms to perform postpartum exercises. Also a practical strategies for postpartum exercises for the women at the previously mentioned stages.

\subsubsection{Implementation Phase}

During implementation phase the intervention was applied using TTM constructs; stages of change, decisional balance, self-efficacy and process of change related to exercises behaviour. Knowledge has been suggested to influence behaviour, and included as a determinant of change. The intervention focused on providing appropriate strategies based on women' motivation to change. In addition, inducing changes in motivation and determinants of change using stagetargeted intervention. The researchers implemented the TTM of change-based behavioural intervention and gave women stage-matched intervention materials with explanation for them. The researchers explained the educational materials and guided the participants to focus on the part of the booklet that related to their own stages of change. According to visits' time schedule of participants, they were interviewed in a private room at outpatient clinic. The intervention involved two sessions which conducted to a small group (5-6) of the women. The duration of each session continued from 30 minutes to 45 minutes including periods of discussion base on their 
development and feedback. At the beginning of the first session an orientation to the intervention and its purpose taken place. Feedback was given at the beginning of each session about the previous one. Different teaching strategies were used such as lectures, group discussions, critical thinking and problem solving. Helpful tools that function as stimulus control to support desired changes include stickers and flyers that reinforce the intervention.

\subsubsection{Evaluation Phase}

Evaluation was applied by comparing knowledge and behaviour change regarding postpartum exercises before and after implementation of the intervention based on TTM. The post-test was done six months after intervention to evaluate the effect of the implemented intervention.

\subsection{Statistical Analysis}

Data analysis was performed using Statistical Package for Social Sciences (SPSS version 20). Descriptive statistics were applied (e.g. frequency, percentages, mean, and standard deviation). Test of significance (paired t test, fisher's exact test and chi-square test) was used to test the study hypothesis. Correlation coefficient was calculated between TTM construct, total knowledge scores and stage of postpartum exercises behaviour change. A significant difference was considered at $\mathrm{p}$-value $\leq .05$.

\section{Results}

Table 1 demonstrates demographic characteristics and obstetric history of the studied participants. It was clear that $48.8 \%$ of the studied women was aged from $30-<35$ years, with a mean age 28.88 \pm 5.89 years. Regarding women' educational qualification, $41.9 \%$ of them had secondary education. Moreover, $72.1 \%$ of them were housewives. More than half of them (51.2\%) reported insufficient monthly income. In addition, 58.1\% of the women were resident in rural areas. The mean number of their BMI and children were $30.22 \pm 4.54$ and $2.06 \pm 1.02$ respectively. As regards their obstetric history, 58.1\% of the women were multipara and the majority (93.0\%) of them were lactating women.

Table 2 declares that, a significant difference was observed $(\mathrm{P}=0.000)$ before and after the intervention in regarding to the stages of change for postpartum exercises behavior. It was clear that, $69.7 \%$ of the women were at the contemplation stages before the intervention, while after the intervention $44.2 \%$ and $20.9 \%$ of them were at action and maintenance stages, respectively.

Table 1. Distribution of the study participants according to their socio-demographic characteristics, and obstetric history $(n=86)$

\begin{tabular}{|c|c|c|}
\hline Characteristics & No & $\%$ \\
\hline \multicolumn{3}{|l|}{ Age } \\
\hline$-<20$ & 6 & 7.0 \\
\hline$-20-<30$ & 42 & 48.8 \\
\hline$-30-<35$ & 26 & 30.2 \\
\hline$-\leq 35$ & 12 & 14.0 \\
\hline Mean \pm SD & \multicolumn{2}{|c|}{$28.88 \pm 5.89$} \\
\hline \multicolumn{3}{|l|}{ Educational qualification } \\
\hline - Primary or preparatory education & 18 & 20.9 \\
\hline - Secondary education & 36 & 41.9 \\
\hline - University education & 32 & 37.2 \\
\hline \multicolumn{3}{|l|}{ Occupation } \\
\hline - Housewife & 62 & 72.1 \\
\hline - Work & 24 & 27.9 \\
\hline \multicolumn{3}{|l|}{ Monthly income } \\
\hline - Insufficient & 44 & 51.2 \\
\hline - Sufficient & 30 & 34.9 \\
\hline - Sufficient and save & 12 & 14.0 \\
\hline \multicolumn{3}{|l|}{ Residence } \\
\hline - Rural & 50 & 58.1 \\
\hline - Urban & 36 & 41.9 \\
\hline Body Mass Index (BMI) (Mean \pm SD) & \multicolumn{2}{|c|}{$30.22 \pm 4.54$} \\
\hline Number of children (Mean \pm SD) & \multicolumn{2}{|c|}{$2.06 \pm 1.02$} \\
\hline \multicolumn{3}{|l|}{ Parity } \\
\hline - Primipara & 36 & 41.9 \\
\hline - Multipara & 50 & 58.1 \\
\hline \multicolumn{3}{|l|}{ Lactation } \\
\hline - Lactating & 80 & 93.0 \\
\hline - Non lactating & 6 & 7.0 \\
\hline
\end{tabular}

Table 2. Distribution of the study participants by the stages of change in postpartum exercises behavior pre and post intervention (n= 86).

\begin{tabular}{|c|c|c|c|c|c|c|}
\hline \multirow{2}{*}{ Stages of change } & \multicolumn{2}{|c|}{ Pre-intervention } & \multicolumn{2}{|c|}{ Post-intervention } & \multirow[b]{2}{*}{$\chi^{2}$} & \multirow{2}{*}{$P$ value } \\
\hline & No & $\%$ & No & $\%$ & & \\
\hline - Pre contemplation & 14 & 16.3 & - & - & 23.490 & $0.000 *$ \\
\hline - Contemplation & 60 & 69.7 & 5 & 5.8 & & \\
\hline - Preparation & 12 & 14.0 & 25 & 29.1 & & \\
\hline - Action & - & - & 38 & 44.2 & & \\
\hline - Maintenance & - & - & 18 & 20.9 & & \\
\hline
\end{tabular}

$\chi \mathbf{2}=$ Chi-squared test, $*$ statistically significant difference at $\mathrm{P} \leq 0.05$.

Table 3. Distribution of the studied participants according to their knowledge toward postpartum exercises (n=86).

\begin{tabular}{|c|c|c|c|c|c|c|c|c|c|c|c|c|c|c|}
\hline \multirow{3}{*}{ Items } & \multicolumn{6}{|c|}{ Pre-intervention } & \multicolumn{6}{|c|}{ Post-intervention } & \multirow{3}{*}{ FET } & \multirow{3}{*}{$P$ value } \\
\hline & \multicolumn{2}{|c|}{$\begin{array}{l}\text { Correct } \\
\text { answer }\end{array}$} & \multicolumn{2}{|c|}{$\begin{array}{l}\text { Incomplete } \\
\text { answer }\end{array}$} & \multicolumn{2}{|c|}{ Don't know } & \multicolumn{2}{|c|}{$\begin{array}{l}\text { Correct } \\
\text { answer }\end{array}$} & \multicolumn{2}{|c|}{$\begin{array}{l}\text { Incomplete } \\
\text { answer }\end{array}$} & \multicolumn{2}{|c|}{ Don't know } & & \\
\hline & No & $\%$ & No & $\%$ & No & $\%$ & No & $\%$ & No & $\%$ & No & $\%$ & & \\
\hline - Definition of postnatal exercises & 14 & 16.3 & 24 & 27.9 & 48 & 55.8 & 37 & 43.0 & 45 & 52.3 & 4 & 4.7 & 102.603 & $0.000^{*}$ \\
\hline $\begin{array}{l}\text { - The proper time to engage in postnatal } \\
\text { exercises }\end{array}$ & 20 & 23.3 & 30 & 34.9 & 36 & 41.9 & 38 & 44.2 & 36 & 41.9 & 12 & 14.0 & 73.555 & $0.000^{*}$ \\
\hline - Benefits of postnatal exercises & 3 & 3.5 & 45 & 52.3 & 38 & 44.2 & 48 & 55.8 & 32 & 37.2 & 6 & 7.0 & 19.463 & $0.000 *$ \\
\hline - Preparation before exercises & 5 & 5.8 & 19 & 22.1 & 62 & 72.1 & 12 & 14.0 & 62 & 72.1 & 12 & 14.0 & 11.641 & $0.001^{*}$ \\
\hline $\begin{array}{l}\text { - Contraindication on postnatal } \\
\text { exercises }\end{array}$ & 12 & 14.0 & 30 & 34.9 & 44 & 51.2 & 51 & 59.3 & 31 & 36.0 & 4 & 4.7 & 54.689 & $0.000^{*}$ \\
\hline - Different types of postnatal exercises & 8 & 9.3 & 12 & 14.0 & 66 & 76.7 & 31 & 36.0 & 40 & 46.5 & 15 & 17.4 & 18.179 & $0.000 *$ \\
\hline - Warning symptoms & 6 & 7.0 & 24 & 27.9 & 56 & 65.1 & 30 & 34.9 & 43 & 50.0 & 13 & 15.1 & 20.730 & $0.000 *$ \\
\hline
\end{tabular}

FET $=$ Fisher's Exact Test, *statistically significant difference at $\mathrm{P} \leq 0.05$. 
Table 3 illustrates that a significant differences were present $(\mathrm{P}<0.05)$ before and after the intervention in relation to women' knowledge about definition, proper time, preparation, contraindication, types and warning symptoms of postpartum exercises.

Table 4 Displays significant differences $(\mathrm{P}<0.05)$ before and after the intervention based on TTM in relation to all items related to self-efficacy toward postpartum exercises behavior.

Table 5 clarifies that pros and cons of the decisional balance were significantly different $(\mathrm{P}<0.05)$ before and after the intervention based on TTM.
Table 6 portrays a significant difference between results $(\mathrm{P}=0.000)$ before and after intervention based on TTM in relation to experiential processes of change (consciousness raising, environmental re-evaluation, social liberation, dramatic relief, self-re-evaluation). Also statistically significant differences $(\mathrm{P}=0.000)$ were found concerning Behavioural processes after intervention based on TTM.

Table 7 shows general improvements $(\mathrm{P}=0.000)$ in the mean scores of all TTM construct include (self-efficacy, pros, cons and experiential and behavioural processes) and total knowledge after the intervention based on TTM as compared to before intervention.

Table 4. Distribution of the studied participants according to their self-efficacy toward postpartum exercises behavior (n=86)

\begin{tabular}{|c|c|c|c|c|c|c|c|c|c|c|}
\hline \multirow[b]{2}{*}{ Self-efficacy Statements } & \multicolumn{4}{|c|}{$\underline{\text { Pre-intervention }}$} & \multicolumn{4}{|c|}{$\underline{\text { Post-intervention }}$} & \multirow[t]{2}{*}{ FET } & \multirow[t]{2}{*}{ P value } \\
\hline & 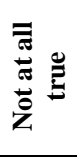 & 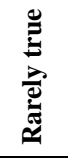 & 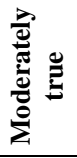 & 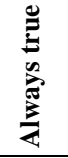 & 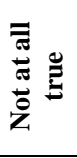 & 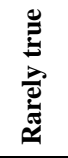 & 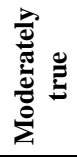 & 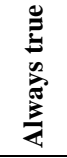 & & \\
\hline & $\%$ & $\%$ & $\%$ & $\%$ & $\%$ & $\%$ & $\%$ & $\%$ & & \\
\hline - I can overcome challenges if I try hard enough with regard to exercises. & 37.2 & 41.9 & 17.4 & 3.5 & 8.1 & 9.3 & 30.3 & 52.3 & 30.141 & $0.000^{*}$ \\
\hline - I can find ways to be physically active in exercises. & 48.8 & 34.9 & 11.6 & 4.7 & 14.0 & 11.6 & 53.5 & 20.9 & 31.185 & $0.000^{*}$ \\
\hline - I can achieve goals that I set for my physical activity and exercises. & 65.1 & 17.4 & 12.8 & 4.7 & 11.6 & 26.7 & 43.0 & 18.6 & 39.014 & $0.000 *$ \\
\hline - I can find solutions to remove a barrier to exercises. & 58.1 & 18.6 & 12.8 & 10.5 & 12.8 & 9.3 & 51.2 & 26.7 & 36.087 & $0.000^{*}$ \\
\hline - I can practice exercises even when I am tired. & 55.8 & 20.9 & 14.0 & 9.3 & 14.0 & 60.5 & 10.5 & 15.1 & 18.031 & $0.030 *$ \\
\hline - I can practice exercises when I am feeling depressed. & 54.7 & 17.4 & 14.0 & 14.0 & 19.8 & 41.9 & 15.1 & 23.3 & 35.772 & $0.000 *$ \\
\hline - I can be physically active without the support of my family or friends. & 53.5 & 26.7 & 5.8 & 14.0 & 12.8 & 10.5 & 38.4 & 38.4 & 57.595 & $0.000^{*}$ \\
\hline - I can be practice exercises without the help of a therapist . & 64.0 & 18.6 & 12.8 & 4.7 & 17.4 & 10.5 & 30.2 & 41.9 & 48.076 & $0.000^{*}$ \\
\hline - I can motivate myself to be exercising again after I've stopped for a while. & 44.2 & 27.9 & 14.0 & 14.0 & 12.8 & 19.8 & 51.2 & 16.3 & 44.117 & $0.000^{*}$ \\
\hline $\begin{array}{l}\text { - I can be physically active or exercises even if I had no access to a gym, } \\
\text { exercises or training. }\end{array}$ & 51.2 & 23.3 & 16.3 & 9.3 & 16.3 & 23.3 & 36.0 & 24.4 & 47.671 & $0.000^{*}$ \\
\hline
\end{tabular}

- FET = Fisher's Exact Test, *statistically significant difference at $\mathrm{P} \leq 0.05$.

Table 5. Distribution of the studied participants according to their decisional balance (Pros and cons) toward postpartum exercises behavior pre and post intervention $(\mathbf{n}=\mathbf{8 6})$

\begin{tabular}{|c|c|c|c|c|c|c|c|c|c|c|c|c|}
\hline \multirow[b]{2}{*}{ Decisional Balance Statements } & \multicolumn{5}{|c|}{ Pre-intervention } & \multicolumn{5}{|c|}{ Post-intervention } & \multirow[t]{2}{*}{ FET } & \multirow[t]{2}{*}{$P$ value } \\
\hline & 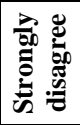 & 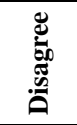 & 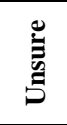 & 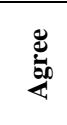 & 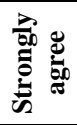 & 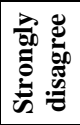 & 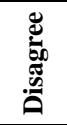 & 莺 & 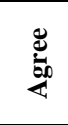 & 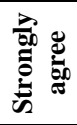 & & \\
\hline Pros & $\%$ & $\%$ & $\%$ & $\%$ & $\%$ & $\%$ & $\%$ & $\%$ & $\%$ & $\%$ & & \\
\hline $\begin{array}{l}\text { - If I exercised regularly .I would be more active for my family } \\
\text { and friends. }\end{array}$ & 26.7 & 34.9 & 14.0 & 9.3 & 15.1 & 20.9 & 7.0 & 20.9 & 37.2 & 34.9 & 81.600 & $0.000^{*}$ \\
\hline - Regular exercises relieve tension. & 4.7 & 36.0 & 41.8 & 14.0 & 3.5 & 0.0 & 14.0 & 37.2 & 34.9 & 14.0 & 78.241 & $0.000 *$ \\
\hline - If I exercised regularly.I would be more confident & 37.2 & 27.9 & 8.1 & 15.1 & 11.6 & 7.0 & 14.0 & 0.0 & 55.8 & 23.3 & 26.504 & $0.002 *$ \\
\hline - If I exercised regularly.I would sleep more soundly & 26.7 & 40.7 & 9.3 & 12.8 & 10.5 & 7.0 & 12.8 & 44.2 & 23.3 & 12.8 & 83.544 & $0.000 *$ \\
\hline - If I exercised regularly I would feel good about myself. & 11.6 & 25.6 & 54.7 & 5.8 & 2.3 & 4.7 & 3.5 & 36.0 & 48.8 & 7.0 & 58.779 & $0.000 *$ \\
\hline - If I exercised regularly. My body would be better & 11.6 & 3.5 & 46.5 & 31.4 & 7.0 & 0.0 & 0.0 & 14.0 & 41.9 & 44.2 & 98.249 & $0.000^{*}$ \\
\hline $\begin{array}{l}\text { - If I exercised regularly .I would perform routine physical } \\
\text { tasks- }\end{array}$ & 5.8 & 41.9 & 27.9 & 14.0 & 10.5 & 0.0 & 7.0 & 48.8 & 37.2 & 7.0 & 77.268 & $0.000^{*}$ \\
\hline - I would feel less stressed if I exercised regularly. & 32.6 & 7.0 & 32.6 & 22.1 & 5.8 & 0.0 & 0.0 & 41.9 & 23.3 & 34.9 & 64.266 & $0.000 *$ \\
\hline - If I exercised regularly.I would be more comfortable . & 24.4 & 19.8 & 31.4 & 18.6 & 5.8 & 3.5 & 29.1 & 2.3 & 34.9 & 30.2 & 94.567 & $0.000^{*}$ \\
\hline $\begin{array}{l}\text { - Regular exercises would help me have a positive view on } \\
\text { life. }\end{array}$ & 32.6 & 38.4 & 7.0 & 9.3 & 12.8 & 4.7 & 5.8 & 39.5 & 26.7 & 23.3 & 42.704 & $0.000 *$ \\
\hline \multicolumn{13}{|l|}{ Cons } \\
\hline - I feel too exhausted to do my daily work after exercising. & 8.1 & 3.5 & 9.3 & 46.5 & 32.6 & 20.9 & 37.2 & 27.9 & 14.0 & 0.0 & 73.781 & $0.000 *$ \\
\hline $\begin{array}{l}\text { - It would be difficult finding an exercises that I like and not } \\
\text { affected by bad weather. }\end{array}$ & 3.5 & 19.8 & 12.8 & 45.3 & 18.6 & 14.0 & 55.8 & 14.0 & 16.3 & 0.0 & 76.773 & $0.000 *$ \\
\hline $\begin{array}{l}\text { - I feel uncomfortable during practicing exercises because my } \\
\text { heart beats fast and get out of breath. }\end{array}$ & 3.5 & 8.1 & 16.3 & 31.4 & 40.7 & 0.0 & 30.2 & 27.9 & 14.0 & 27.9 & 80.136 & $0.000^{*}$ \\
\hline - Regular exercises take too much of my time. & 2.3 & 3.5 & 11.6 & 37.2 & 45.3 & 0.0 & 16.3 & 41.9 & 41.9 & 0.0 & 43.854 & $0.000^{*}$ \\
\hline $\begin{array}{l}\text { - If I exercised regularly, I would have less time for my family } \\
\text { and friends,. }\end{array}$ & 3.5 & 12.8 & 3.5 & 51.2 & 29.1 & 20.9 & 37.2 & 27.9 & 14.0 & 0.0 & 54.217 & $0.000 *$ \\
\hline $\begin{array}{l}\text { - I am too tired to practice exercises specially at the end of the } \\
\text { day. }\end{array}$ & 3.5 & 4.7 & 19.8 & 47.7 & 24.4 & 20.9 & 27.9 & 37.2 & 0.0 & 14.0 & 56.316 & $0.000^{*}$ \\
\hline
\end{tabular}

FET $=$ Fisher's Exact Test, $*$ statistically significant difference at $\mathrm{P} \leq .05$. 
Table 6. Mean scores of experiential and behavioural processes toward postpartum exercises behavior among the study participants before and after the intervention $(n=86)$

\begin{tabular}{lccccc}
\hline Items & Maximum score & Pre-intervention & Post-intervention & Paired t test & P value \\
\hline Experiential processes & & & & & \\
1. Consciousness raising & 6 & $2.06 \pm 0.95$ & $3.93 \pm 0.87$ & 20.828 & $0.000^{*}$ \\
2. Environmental re-evaluation & 6 & $2.23 \pm 0.68$ & $4.79 \pm 0.93$ & 21.323 & $0.000^{*}$ \\
3. Social liberation & 6 & $2.00 \pm 0.84$ & $4.09 \pm 1.43$ & 11.667 & $0.000^{*}$ \\
4. Dramatic relief & 6 & $2.44 \pm 0.72$ & $3.95 \pm 1.33$ & 17.046 & $0.000^{*}$ \\
5. Self-re-evaluation & 6 & $2.41 \pm 1.23$ & $4.41 \pm 0.81$ & 20.152 & $0.000^{*}$ \\
Behavioural processes & & & & & $0.000^{*}$ \\
6. Self-liberation & 6 & $2.62 \pm 01.38$ & $3.62 \pm 1.36$ & 42.204 & $0.000^{*}$ \\
7. Counter-conditioning & 6 & $1.97 \pm 1.00$ & $4.04 \pm 1.03$ & 5.156 & $0.000^{*}$ \\
8. Stimulus control & 6 & $2.62 \pm 1.22$ & $3.20 \pm 1.19$ & 26.291 & $0.000^{*}$ \\
9. Reinforcement management & 6 & $1.86 \pm 0.82$ & $3.13 \pm 0.63$ & 26.511 & $0.000^{*}$ \\
10. Helping relationships & 6 & $2.67 \pm 1.05$ & $4.09 \pm 0.88$ & 20.828 & $0.000^{*}$ \\
\hline
\end{tabular}

* Statistical significant difference $(\mathrm{P} \leq .05)$.

Table 7. Mean differences of subtotal TTM construct and total knowledge scores of the study participants between pre and post intervention $(\mathbf{n}=\mathbf{8 6})$

\begin{tabular}{lccccc}
\hline Items & Maximum score & Pre-intervention & Post-intervention & Paired t test & P value \\
\cline { 1 - 6 } TTM constructs score & & & & & \\
- Self-efficacy & 40 & $17.75 \pm 6.76$ & $30.37 \pm 5.70$ & 18.782 & $0.000^{*}$ \\
- Decisional balance (Pros) & 50 & $24.19 \pm 5.98$ & $36.68 \pm 3.55$ & 20.267 & $0.000^{*}$ \\
- Decisional balance (Cons) & 30 & $19.74 \pm 3.26$ & $12.15 \pm 4.09$ & 14.252 & $0.000^{*}$ \\
- Experiential processes & 30 & $11.16 \pm 2.51$ & $21.18 \pm 2.92$ & 24.843 & $0.000^{*}$ \\
- Behavioral processes & 30 & $11.76 \pm 2.76$ & $18.11 \pm 2.98$ & 44.096 & $0.000^{*}$ \\
Total knowledge score & 14 & $4.72 \pm 2.86$ & $10.10 \pm 2.29$ & 26.129 & $0.000^{*}$ \\
\hline
\end{tabular}

*A statistical significant difference $(\mathrm{P} \leq 0.05)$.

Table 8. Correlation coefficient between study subjects' subtotal scores of TTM constructs, total knowledge score and their stage of postpartum exercises behaviour before and after intervention $(n=86)$

\begin{tabular}{|c|c|c|c|c|c|}
\hline \multirow{3}{*}{ Variables } & \multicolumn{5}{|c|}{ The stages of postpartum exercises behavior } \\
\hline & & \multicolumn{2}{|c|}{ Pre-intervention } & \multicolumn{2}{|c|}{ Post-intervention } \\
\hline & & $r$ & $\boldsymbol{P}$ & $r$ & $P$ \\
\hline \multicolumn{6}{|l|}{ TTM construct } \\
\hline \multirow[t]{2}{*}{ - Self-efficacy } & Pre-intervention & 0.657 & $0.000^{*}$ & & \\
\hline & Post-intervention & & & 0.439 & $0.000^{*}$ \\
\hline \multirow[t]{2}{*}{ - Decisional balance_(pros) } & Pre-intervention & 0.304 & $0.004 *$ & & \\
\hline & Post-intervention & & & 0.536 & $0.000^{*}$ \\
\hline \multirow[t]{2}{*}{ - Decisional balance_(Cons) } & Pre-intervention & -0.248 & $0.021^{*}$ & & \\
\hline & Post-intervention & & & -0.530 & $0.000 *$ \\
\hline \multirow[t]{2}{*}{ - Experiential processes } & Pre-intervention & 0.420 & $0.000^{*}$ & & \\
\hline & Post-intervention & & & 0.740 & $0.000 *$ \\
\hline \multirow[t]{2}{*}{ - Behavioral processes } & Pre-intervention & 0.819 & $0.000^{*}$ & & \\
\hline & Post-intervention & & & 0.566 & $0.000 *$ \\
\hline \multirow[t]{2}{*}{ Total knowledge score } & Pre-intervention & 0.666 & $0.000^{*}$ & & \\
\hline & Post-intervention & & & 0.302 & $0.005^{*}$ \\
\hline
\end{tabular}

*A statistical significant difference $(\mathrm{P} \leq 0.05)$.

Table 8 indicates a positive correlation $(\mathrm{P}<0.05)$ between studied postpartum women' scores of self-efficacy, decisional balance pros, experiential and behavioural processes and their stage of postpartum exercises behavior change. On the other hand a negative, significant correlation $(\mathrm{P}<0.05)$ were observed between women' cones scores and their stage of postpartum exercises behavior change before and after the intervention. Moreover, a positive correlation $(\mathrm{P}<0.05)$ between postpartum women' total knowledge score and their stages of postpartum exercises behavior before and after the intervention based on TTM.

Figure 1 portrays that, $24.4 \%$ of the studied women had moderate level of physical activity pre-intervention. Meanwhile post intervention the moderate level become 43.0\%. Moreover, there was a significant difference between results $(\mathrm{P}=0.036)$ before and after intervention.

Figure 2 shows that, $86.0 \%$ of the studied women who developed in stages of change after intervention based on TTM, $12.8 \%$ of them stayed in the same stages (stationary). Only $1.2 \%$ of them were regressed from the pre-program stage. 


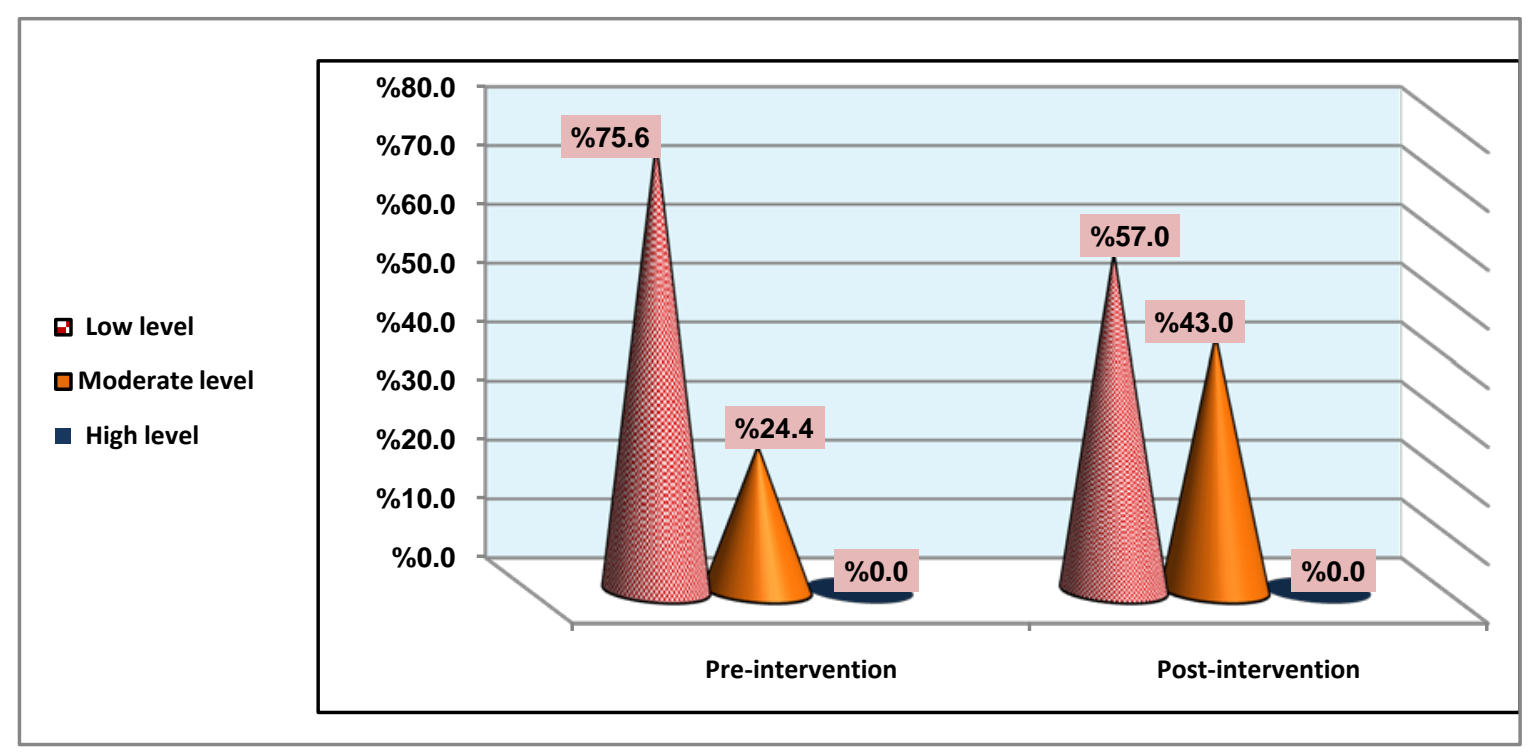

(Fisher's Exact Test $=16.235, \mathrm{P}=0.036 *$ )

Figure 1. Distribution of the study subject according to their level of physical activity pre and post- intervention $(\mathbf{n}=\mathbf{8 6})$

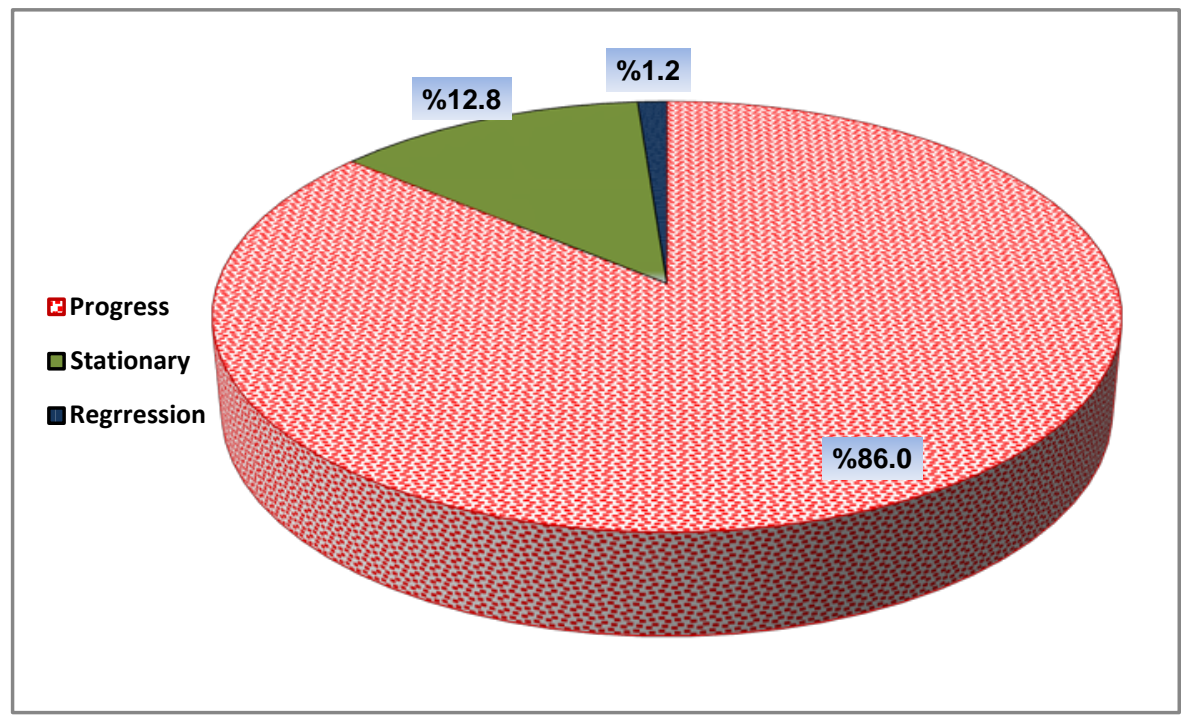

Figure 2. Stage movement from pre- intervention to post- intervention $(n=86)$

\section{Discussion}

Postpartum physical exercises is the physical activity done after childbirth. The purpose of physical exercise is to maintain a valuable level of fitness, physical and mental health. Postpartum physical exercise should be encouraged, they help to improve abdominal and pelvic floor muscles tone. Physical exercise can be relaxing as it will help the body recover, and ensure keep fit. [31] Assessing women knowledge and behavior towards postpartum exercise helps healthcare professional to create educational interventions that improve postpartum exercise knowledge and behavior among childbearing women. [32]

Behavioural models and theories should be used to help individuals better understand various behaviours. The TTM has been presented as a comprehensive model that provide the opportunity of making the decision of an appropriate treatment plan for the individual. Also it has revealed positive effects on individuals with different risk behaviours related to non-communicable diseases. [33,34] With regard to the low level of physical activity in females and the role of TTM in determining effective factors behind behaviour, there should be an attempt to develop continuous and organized educational interventions to enhance physical exercise in women by using the TTM. [35] Therefore, the current study conducted with a view to assess the effect of a TTM based intervention on postpartum exercises behaviour among puerperas as part of the safe motherhood.

The current study had been evaluated the knowledge of the studied postpartum women regarding postpartum exercises before and after intervention based TTM, therefore, the results of the current study pointed out that the studied women had deficient knowledge below the average level about postpartum exercises before the educational intervention based TTM. Their low scores of knowledge may be attributed to that most of the studied women had preparatory and secondary education, as well as the severe lack of implementation of educational 
programs in this regard. The results of this study are consistent with the results of at least three other studies. First, Sreenivasan [31] who had assessed "the knowledge of postpartum mother's regarding postpartum physical exercise". He found that very low percentage of the mothers had adequate knowledge regarding the postpartum exercise and added that there is a need for educational interventions regarding postpartum exercise among puerperas. Second, Mbombi, et al. [11] who had evaluated puerperas' knowledge regarding postpartum exercise in South Africa. Found that there was lacked knowledge regarding postpartum exercise and a high rate of ignorance among postnatal mothers regarding the importance of postpartum exercise. Third, Sarkar et al. [36] who had studied "knowledge and practice regarding postpartum exercises among puerperas". Their study indicated that there was insufficient knowledge concerning postpartum exercises among puerperas. Also, recommended the implementation of an educational intervention on postnatal exercises by the nurse to improve puerperas' knowledge and practice.

On the contrary, Alharqi \& Albattawi and Abedzadeh et al. $[32,37]$ had recorded different results. Where is the former had evaluated "the knowledge and attitude of women towards postpartum exercise in King Abdulaziz University Hospital at Saudi Arabia" they found that more than two-thirds of the women had adequate knowledge regarding postpartum exercise. The latter, who had assessed "knowledge of pregnant women regarding postpartum physical exercise". Revealed that the most of their studied subjects had a moderate level of knowledge about exercise during postpartum period. The dissimilarity between the present study findings and the latter two studies may be due to the difference in the place of studies and cultural background of targeted population where the current study conducted in Egypt while the latter two studies conducted at Saudi Arabia and Iran.

Furthermore, the current study results showed significant improvement in the post intervention stage on women' knowledge regarding definition, proper time, preparation, contraindication, types and warning symptoms of postpartum exercises. This improvement of knowledge post intervention might be reflect the effect of the TTM based intervention on increasing knowledge and awareness in this regard. These findings are in agreement with at least other four studies. First, Mistry et al. [38] who had studied "knowledge of postpartum mothers toward postpartum exercises". Found significant improvement in mothers knowledge regarding postnatal exercise after administration of planned teaching program. Second, Ramchandra et al. [5] who had studied "knowledge of primigravida mothers regarding postnatal exercise". Reported that after seven days in post-test of structured teaching program, more than two-thirds of the mothers were having average knowledge. Third, Kalariya [4] who had reported adequate knowledge and awareness among postnatal mother after application of structured teaching programme regarding postnatal exercises based on Orem's self-care model. Fourth, Christie et al. [39] who had concluded that planned educational programme was highly effective in enhancing puerperas' knowledge toward postnatal physical exercise.

The readiness for change, evaluated in the current research as a continuous variable, relates to how ready the woman believes herself to be to modify her habits of postpartum physical exercise. The finding of the current study showed statistically significant difference $(\mathrm{P}=0.000)$ before and after the intervention in relation to the readiness of change for postpartum exercises behavior. Where more than half of the studied women were at the contemplation stage before the intervention, while after the intervention about two-thirds of them were at the action and maintenance stages. This finding suggests that the educational intervention based on TTM helps to motivate and develop the readiness of change and proves the effectiveness of the intervention. In this regard Boff et al. [40] who had conducted a randomized control trial to evaluate the effect of TTM for change in obese adolescents. They stated that the most significant results in their study were related to readiness for change. In addition, Holmen et al.[41] who had found that 79\% of their participants were in the contemplation and preparation stages for physical exercise and indicated a requirement to provide more continual support for physical activity change through intervention based on TTM. Moreover, Huang et al.[42] who had applied TTM among pregnant women in Taiwan, indicated significant improvement in the study group regarding the stages of change after intervention based on TTM. Where the most of their studied subjects were in post-action stages after joining in TTM based intervention program.

Additionally, the finding of current study pointed out that, more than three-quarters of the studied women progressed in stages of change to action and maintenance stages after the intervention based on TTM. This finding in the same line with Moosavi et al. and Farmanbar et al. $[43,44]$ they demonstrating a significant improve in the level of physical exercise and participants' progression in stage of change after the intervention based on TTM. Another study applied the TTM in Turkey, was conducted by Koyun and Eroğlu [45] reported that the rate of progression to action or maintenance stages were higher in the study group than in the control group after intervention based on TTM. In addition, the study of Mastellos et al. [46] agreed with our study findings which showed an improvement in exercise behavior among participants, as well as progress to the post-action stages in the study group as compared to control group.

Regarding the mediators of behavior change (TTM constructs) toward postpartum exercises behavior modification among the studied women, the results of the present study displayed general improvements in the mean scores of all mediators of behavior change which include; self-efficacy, decisional balance ( pros) and experiential and behavioural process of change toward postpartum exercises behavior of the studied women after TTM based intervention with a statistical significant difference as compared to before the intervention $(P=0.000)$. These results recommend that the intervention based TTM is more effective in improving self-efficacy, decisional balance pros and cons toward postpartum exercises behavior.

These results are similar to the results of at least seven other researches. The first, Motlagh et al. [47] who had showed a significant difference between the intervention and control groups for physical exercise stages of change, processes of change, duration, intensity and frequency of 
walking at three and six months post-intervention. The second, the previously mentioned Moosavi et al. [43] who had stated that TTM-based educational program seems to improve the mean score of self-efficacy and decisional balance. The third, Abdi et al. [48] in their systematic review study in Iran. Stated that all TTM based studies, documented positive findings in the intervention group as compared to control group. The fourth, Jalilian et al. [49] who had implemented "intervention program based on TTM to promote physical exercise among office workers" showed a significant improvement in all constructs of TTM, and the level of knowledge. The fifth, Moeini et al. [50] who had reported a significant difference in physical activity; also, improve the cognitive and behavioral processes scores as well as self-efficacy score. The sixth, Dishman et al. [51] who had conducted longitudinal cohort study to predict classes of change in regular physical exercise. Highlighted the effect of TTM-based programs on the promotion of physical exercises and claimed that TTM is effective in process of change. The seventh, Mahmoodabab et al. [52] who had applied the TTM to exercise in office staff. Indicated significant variances between decisional balance, behavioral and cognitive process with the stages of change.

The correlations between women' score of TTM construct, total knowledge score and their stage of change toward postpartum exercises behaviour were took place in the this study. Accordingly, there were a positive, significant correlations ( $\mathrm{P}=0.000$ ) between the women' scores of total knowledge, self-efficacy, decisional balance pros, process of change with their stage of change toward postpartum exercises behaviour before and after the intervention. This means that the studied women in the action, and maintenance stages have a higher sores of knowledge, self-efficacy, decisional balance (pros), experiential and behavioural processes as compared to those in the preparation and contemplation and pre contemplation stages. These results were supported by at least three other researches. First, Pirzadeh et al. [35] who had applied TTM to identify physical activity behavior in women through a cross-sectional survey. Found that the stages of change significantly correlated with the decisional balance, processes of change, and self-efficacy. Second Han et al. [53] who had reported that the mean scores of the TTM constructs increased as the stages progressed and found statistically positive correlation between self-efficacy construct and the stages of change. Third Rosenkranz et al. [54] who found that the women in the post-action stages had lower BMI than those in pre-action stages ( $\mathrm{p}<0.05)$. Fourth, Roozbahani et al. [17] who had reported a significant correlations between stage of change and pros, cons, and self-efficacy. Fifth, Vahedian et al. [55] who had assessed physical exercise among Iranian girls based on TTM. Reported a significant correlations $(\mathrm{P}=0.011)$ between stage of change, physical exercise level, self-efficacy, and decisional balance.

Moreover, the current study showed a negative, statistically significant correlation $(\mathrm{P}<0.000)$ between studied women' decisional balance cons (obstacles to being physically active) score and their stage of change before and after the intervention. This means that the women in the latter stages (action, and maintenance) have lower sores of decisional balance cons, as compared to those in the preparation, contemplation and pre-contemplation stages. Low con scores in the latter stages (action, and maintenance) also suggest that women have perceived fewer cons about postpartum exercise. This result was in agreement with the study conducted by Ibrahim et al. [56] who had documented that the cons significantly declined across the stages of change, where their studied subjects in contemplation and preparation stages scored higher than those in action and maintenance stages. Also, Keshani and Farvid [57] who had stated that the decisional balance cons was significantly different across the stages of change; in the pre-action stages it was higher than in the post-action stages.

An important finding from the current study is that physical exercise activity variable was significantly $(\mathrm{P}<0.05)$ different before and after intervention. Whereas, about one-quarter of the studied women had moderate level of physical activity pre-intervention. Meanwhile, in the post intervention the moderate level become $43.0 \%$. In this regard Wilson et al. [58] who had also applied the TTM to physical activity behavior, and showed statistically significant difference $(\mathrm{P}<0.05)$ before and after intervention regarding the level of physical activity and concluded that the constructs of the TTM appear to be important at different stages of change. Moreover, previously mentioned Roozbahani et al. [17] support the application of TTM to postpartum exercise behaviour change among Iranian postnatal mothers. Furthermore, Ishii et al. [59] who had evaluated "the effect of a physical exercise educational intervention using the TTM". Stated that, in order to continue health protective behavior over the long term it may be necessary to incorporate the TTM based interventions to improve physical activities. Consequently, to enhance women' knowledge and improve their physical activity and exercising behavior, emphasis should be made on educational intervention based on TTM and persistent evaluation of their knowledge and behaviors to avoid relapse to a lower stage of behavior change when they meet new barriers or difficulties.

\section{Conclusion}

Based on the results of the current study, it can be concluded that, the above mentioned findings proved and reinforced the research hypothesis. The TTM based intervention was efficient in improving postpartum women's knowledge, physical exercise behavior. This has been observed in increasing women's self-efficacy, decisional balance pros, experimental and behavioral processes of change. While reducing decisional balance cons. The results also highlight the significance of TTM as a useful framework for promoting changes and assessing studied subjects' progress.

\section{Recommendations}

Based on findings of this study, the following recommendations can be proposed:

- $\quad$ The nurse should implement TTM based interventions for postpartum women to promote postpartum exercise behaviour. 
- The nurses should provide all puerperas at outpatient clinics with stage-matched intervention materials to enhance their knowledge and postpartum exercise behaviour.

Further study

- Evaluate the effectiveness of TTM based interventions in physical activity with long term follow up and larger sample size.

\section{References}

[1] Hesketh, K.R., Evenson, K.R., Stroo, M., Clancy, S.M., Ostbye, T. \& Benjamin-Neelon, S.E., Physical activity and sedentary behavior during pregnancy and postpartum, measured using hip and wrist-worn accelerometers, Preventive Medicine Reports , $2018 ; 10$ : 337-345.

[2] Faiza, N.,A., Women's perception and experiences regarding postpartum exercise in Khartoum University Hospitals -Khartoum Locality -2015 Sudan, Indian Journal of Applied Research, 2016 ; 2(6): 1-2.

[3] Duffin C. Postnatal exercise improves muscle tone and relieves back pain. Primary Health Care 2012; 22 (10):6-8.

[4] Kalariya,M., A Study to Assess Effectiveness of Structured Teaching Programme on Knowledge and Practice Regarding Postnatal Exercises among Postnatal Mother in Selected Hospitals of Valsad District. Int. J. Nur. Edu. and Research, 2015; 3(3): 281-283.

[5] Ramchandra, M., Starve, V., Naregal, P., Hiremath, P. \& Salunkhe, A., Knowledge of Primigravida Mothers Regarding Postnatal Exercise. Indian Journal of Applied Research, 2016; 6(7): 1-8.

[6] Davies GA, Wolfies LA, Mottola ME, Mackinnson C. Exercise in pregnancy and the postpartum period. J Obstet Gynaecol Canada 2013; 25(6): 516-529.

[7] Bassett-Gunter, R., Levy-Milne, R., Naylor, P.J., Symons Downs, D., Benoit, C., Warburton, DER., et al. Oh baby! Motivation for healthy eating during parenthood transitions: a longitudinal examination with a theory of planned behavior perspective. Int $\mathrm{J}$ Behav Nutr Phys Act. 2013; 10(1): 88.

[8] American College of Obstetricians and Gynecologists, Physical activity and exercise during pregnancy and the postpartum period. Committee opinion no. 650. Obstet. Gynecol., 2015; 126: 135-42.

[9] Saligheh ,M., McNamara, B., \& Rooney, R., Perceived barriers and enablers of physical activity in postpartum women: a qualitative approach, BMC Pregnancy Childbirth. 2016; 16 (2): 131.

[10] Gaston, A., Cramp, A., \& Prapavessis, H., "Enhancing selfefficacy and exercise readiness in pregnant women," Psychology of Sport and Exercise, 2012; 13(5) : 550-557.

[11] Mbombi, M.O., Thopola, M. K., Kgole, J.C. \& Phil,D., Puerperas' knowledge regarding postpartum exercises in a tertiary hospital in the Capricorn District of Limpopo Province, South Africa, S Afr J Obstet Gynaecol., 2017; 23(1): 3-6.

[12] Beauchamp M, Dunlop WL, Downey SM, Estabrooks PA. First impressions count: Perceptions of surface-level and deep-level similarity within postnatal exercise classes and implications for program adherence. J Health Psychol 2012; 17: 68-72.

[13] Hildebrand, M.\& Neufeld, P., Recruiting Older Adults Into a Physical Activity Promotion Program: Active Living Every Day Offered in a Naturally Occurring Retirement Community, Gerontologist. 2009; 49(5):702-10.

[14] Nigg, C.R., Geller, K.S., Horwath, C.C., Wertin , K.K.\& Dishman, R.K., A Research Agenda to Examine the Efficacy and Relevance of the Transtheoretical Model for Physical Activity Behavior, Psychol Sport Exerc., 2011; 12(1): 7-12.

[15] Prochaska, J.J., Nigg, C.R., Spring, B., Velicer, W.F.\& Prochaska, J.O. The benefits and challenges of multiple health behavior change in research and in practice. Prev Med. 2010; 50(1-2): 26-9.

[16] Armitage, C.J. Can variables from the transtheoretical model predict dietary change? J Behav Med. 2010; 33(4): 264-73.

[17] Roozbahani, N., Ghofranipour, F., Eftekhar Ardebili, H., Hajizadeh, E. The relationship between self-efficacy and stage of change and physical activity behavior in postpartum women. Arak Medical University Journal. 2013; 15(9): 61-71
[18] Peyman, N.\& Abdollahi, M. The relationship between health literacy and self-efficacy physical activity in postpartum women. Journal of Health Literacy, 2016; 1(1): 5-12

[19] Walker ,L.O., Murphey, C.L., Nichols, F. The Broken Thread of Health Promotion and Disease Prevention for Women During the Postpartum Period, J Perinat Educ. 2015; 24(2): 81-92.

[20] Oja, P., Bull, F. C., Fogelholm, M., \& Martin, B. W. Physical activity recommendations for health: What should europe do? BMC Public Health, 2010; 10: 10.

[21] National Nutrition Institute. Obesity. 2012. Available from: http://www.nni.org.eg/obesity_ar.htm.

[22] World Health Organization (WHO) Obesity and Overweight. 2015 Available from: http://www.who.int/mediacentre/factsheets/fs311/ en/ 35.

[23] Austin A, Hill A and Fawzi W (2011): Maternal obesity trends in Egypt 1995-2005. Maternal \& Child Nutrition, 9(2): 167-179.

[24] WHO Department of Maternal, Newborn, Child and Adolescent Health http://www.who.int/maternal_child_adolescent. Postnatal Care Guidelines, March 2015. Available from: https://www.who.int/maternal_child_adolescent/publications/WH O-MCA-PNC-2014-Briefer_A4.pdf.

[25] Marcus BH, Selby VC, Niaura RS, Rossi JS. Self-efficacy and the stage of exercise behavior change. Res Q Exerc Sport. 2002; 63(1) 60-66.

[26] Kroll T, Kehn M, Ho PS, Groah S. The SCI Exercise Self-Efficacy Scale: development and psychometric properties. Int J Behav Nutr Phys Act. 2007; 4: 34. Published 2007 Aug 30.

[27] Marcus, B.. H., Banspach, S. W., Lefebvre, R. L., Rossi, J. S., Carleton, R. A., Abrams, D. B. Using the stages of change model to increase the adoption of physical activity among community participants. American Journal of Health Promotion, 1992; 6. 424-429.

[28] Craig CL, Marshall AL, Sjostrom M, Bauman AE, Booth ML, Ainsworth BE, et al. International physical activity questionnaire: 12-country reliability and validity. Med Sci Sports Exerc. 2003; 35(8): 1381-95.

[29] Sanda B, Vistad I, Haakstad LA, Berntsen S, Sagedal LR, LohneSeiler $\mathrm{H}$, et al. Reliability and concurrent validity of the International Physical Activity Questionnaire short form among pregnant women. BMC Sports Sci Med Rehabil. 2017; 9: 7.

[30] Bozkus T, Turkmen M, Kul M, et al. Determination of physical activity levels and healthy lifestyle behaviors of students in physical education and sports college. Int JSCS. 2013; 1: 49-65.

[31] Sreenivasan, A. study to assess the knowledge, practice and attitude of postnatal mother regarding postnatal exercise in government headquarters hospital, Kumbakonam Asha Sreenivasan, International Journal of Advanced Scientific Research. 2017 July; 2(4): 32-35.

[32] Alharqi, H.\& Albattawi, J.A., Assessment of Knowledge and Attitude of Women Towards Postpartum Exercise, IOSR Journal of Nursing and Health Science, 2018; 7(1): 16-20.

[33] Koyun, A., \& Eroğlu, b.K. The trans theoretical model use for smoking cessation, European Journal of Research on Education, Special Issue: Contemporary Studies in Social Science, 2014; 130-134. Available Online at http://iassr.org/journal.

[34] De Menezes, M.C., Mingoti, S.A., Cardoso,C.S., Mendonça, D. R. \& Lopes, A.C.S . Intervention based on Transtheoretical Model promotes anthropometric and nutritional improvements-A randomized controlled trial. Eating behaviors, 2015; 17: 37-44.

[35] Pirzadeh, A., Mostafavi, F., Ghofarnipour, F., \& Mansourian, M. The Application of the Transtheoretical Model to Identify Physical Activity Behavior in Women, Iran J Nurs Midwifery Res., 2017; 22(4): 299-302.

[36] Sarkar, J., Konwar, G. \& Das, L.K. Assessment of knowledge and practice regarding postnatal exercises among mothers admitted in postnatal ward in Gauhati Medical College and Hospital. Journal of Obstetrics \& Gynaecology Barpeta, 1(1): 52-56.

[37] Abedzadeh, M., Taebi ,M., Sadat, Z.\& Saberi, F., Knowledge and performance of pregnant women referring to Shabihkhani hospital on exercises during pregnancy and postpartum periods, Journal of Jahrom University of Medical Sciences, 2011; 8(4): 1-8.

[38] Mistry, K.R., Bhonsle, M., Chaudhari, C., Chauhan, P., Chauhan, P., Gayakwad,S.,Parmar, K. \& Patel, M.,Knowledge of Postnatal Mothers Regarding Postnatal Exercises, The Journal of Advanced Health Informatics, 2017; 1(1):21-24. 
[39] Christie, S., Koshy, S., Ravindra H.N. \& Damor, R., Effectiveness Of Planned Teaching Programme On Knowledge Regarding Postnatal Exercises Among Postnatal Mothers Admitted In Selected Hospitals Of Vadodara , IOSR Journal of Nursing and Health Science, 2014; 3(6):11-15.

[40] Boff RM, Dornelles MA, Feoli AMP, Gustavo ADS, Oliveira MDS. Transtheoretical model for change in obese adolescents: MERC randomized clinical trial. J Health Psychol. 2018 Aug 16:1359105318793189.

[41] Holmen, H., Wahl, A., Torbjørnsen, A, Jenum, A.K, Småstuen, M.C., \& Ribu, L. Stages of change for physical activity and dietary habits in persons with type 2 diabetes included in a mobile health intervention: the Norwegian study in renewing health. BMJ Open Diabetes Res Care. 2016; 4(1): 1-1. e000193.

[42] Huang, C.M., Wu, H.L., Huang, S.H., Chien, L.Y., Guo, J.L. Transtheoretical model-based passive smoking prevention programme among pregnant women and mothers of young children. Eur J Public Health. 2013; 23(5):777-782.

[43] Moosavi, s., Farmanbar, R., Fatemi, S., Yazdanipour, M.A. The Effect of a TTM-Based Intervention on Level of Physical Activity in ICU Nurses Iran Red Crescent Med J. In Press(In Press):e59033. Published online 2017 December 5.

[44] Farmanbar R, Niknami SH, Heydarnia AR. Effect of an integrated transtheoretical model and self-Determination theory on the promotion and maintenance of exercise behavior. J Guilan Univ Med Sci. 2012; 21(82): 45-56.

[45] Koyun, A., \& Eroğlu, K. The effect of transtheoretical modelbased individual counseling, training, and a 6-month follow-up on smoking cessation in adult women: a randomized controlled trial. Turk J Med Sci. 2016; 46(1): 105-11.

[46] Mastellos, N., Gunn, L.H., Felix, L.M., Car, J.\& Majeed, A., Transtheoretical model stages of change for dietary and physical exercise modification in weight loss management for overweight and obese adults, Cochrane Database of Systematic Reviews 2014, Issue 2. Art. No.: CD008066.

[47] Motlagh,Z., Hidarnia, A., Kaveh,M., H.\& Kojuri ,J., Influence of a Trans-Theoretical Model Based Intervention on Physical Activity in Hypertensive Patients: A Randomised Clinical Trial , Asian J Sports Med., 2017 ; 8(2): 2-9.

[48] Abdi J, Eftekhar H, Estebsari F, Sadeghi R. Theory-based interventions in physical activity: a systematic review of literature in Iran. Glob J Health Sci. 2014; 7(3): 215-29.
[49] Jalilian M, Darabi M, Sharifirad Gh, Kakaei H. Interventional Program based on Trans-Theoretical Model to Promote Regular Physical Activity in Office Workers. J Health Syst Res. 2013; 9(2) 188-19.

[50] Moeini B, Hazavehei S. M, Jalilian M, Moghimbeigi A, Seresht T. Factors Affecting Physical Activity and Metabolic Control in Type 2 Diabetic Women Referred to the Diabetes Research Center of Hamadan: Applying Trans-Theoretical Model. Sci J Hamadan Univ Med Sci. 2011; 18(2): 31-37.

[51] Dishman RK, Vandenberg RJ, Motl RW, Nigg CR. Using constructs of the transtheoretical model to predict classes of change in regular physical activity: a multi-ethnic longitudinal cohort study. Ann Behav Med. 2010; 40(2): 150-63.

[52] Mahmoodabab, S.S.M., Mohammadi, M., \& Abad, M.A.M. Application of Transtheoretical Model to exercise in office staff. Electron Physician. 2013; 5(1): 588-593

[53] Han, H., Gabriel, K.P., Kohl, H.W., Application of the trans theoretical model to sedentary behaviors and its association with physical activity status, 2017; PLoS ONE 12(4): 1-13.

[54] Rosenkranz et al. Validity of the Stages of Change in Steps instrument (SoC-Step) for achieving the physical activity goal of 10,000 steps per Day, BMC Public Health ,2015; 15:1197.

[55] Vahedian M, Alinia A, Attarzadeh R, Esmaeeli H. Assessment of Physical Activity Among Female Students of Tonekabon-Iran Based on Trans-theoretical Model. Thrita. 2013; 2(2): 127-32.

[56] Ibrahim, H.A., Abd Alaal, E.M., El Sayed, H.A. Diet Behavior Modification of Pregnant Woman with Iron Deficiency Anemia Using Construct of the Trans-Theoretical Model: A Theory-Based Study, IOSR Journal of Nursing and Health Science. 2017; 6(3): 1-7.

[57] Keshani, P., \& Farvid, M.S. Association of Self-efficacy and Decisional Balance with Stages of Change for Fiber Intake and Glycemic Control in Patients with Type 2 Diabetes. Nutrition and Food Sciences Research. 2015; 2(4): 11-20.

[58] Wilson JJ, Kirk A, Hayes K, Bradbury I, McDonough S, Tully MA, O'Neill B, Bradley JM. Applying the Transtheoretical Model to Physical Activity Behavior in Individuals With Non-Cystic Fibrosis Bronchiectasis. Respir Care. 2016 Jan;61(1): 68-77.

[59] Ishii A, Nakiri M, Nagatomi K, Tsuji Y, Hoshiko M, Yamaguchi Y, Muramoto J, Ishitake T. Effect of a physical activity improvement program using the transtheoretical model at a smallscale company. Kurume Med J. 2007; 54(1-2): 1-8.

(C) The Author(s) 2019. This article is an open access article distributed under the terms and conditions of the Creative Commons Attribution (CC BY) license (http://creativecommons.org/licenses/by/4.0/). 